\title{
Cellular Mechanisms in the Pathogenesis of Idiopathic Pulmonary Fibrosis
}

\author{
Sandra Cuerpo, MD1, Nuria Albacar, MD¹, and Mauricio Rojas, MD² \\ ${ }^{1}$ Servei de Pneumologia, Respiratory Institute, Hospital Clinic, IDIBAPS, Universitat de Barcelona, Barcelona, Spain; ${ }^{2}$ Division of Pulmonary, Critical Care, \\ \& Sleep Medicine, Davis Heart \& Lung Research Institute, The Ohio State University, Columbus, OH, USA
}

\section{ABSTRACT}

Current evidence suggests that the fibrotic response in idiopathic pulmonary fibrosis (IPF) arises due to accelerated aging of the lung after repeated injuries to the alveolar epithelium, which causes the production of inflammatory mediators that induce the recruitment and activation of lung fibroblasts. These cells are responsible for the secretion of excessive amounts of collagen fibers, destroying the normal lung architecture leading to decreased lung compliance, disrupted gas exchange, and, ultimately, respiratory failure.

Different alterations of cellular function have been proposed to be related to the premature aging of pulmonary tissue in IPF, such as defects in DNA repair, mitochondrial dysfunction, telomeric shortening, loss of protein homeostasis, and cellular senescence.

Improving our understanding of the pathophysiology of this disease is a crucial point to find new therapeutic targets. In the following article, we review recent data on the underlying mechanisms thought to be involved in the pathogenesis of IPF. (BRN Rev. 2021;7(2):82-95) Corresponding author: Mauricio Rojas, mauricio.rojas@osumc.edu

Key words: Cellular aging. Idiopathic pulmonary fibrosis. Lung aging.

Heart \& Lung Research Institute, The Ohio State University, 473 W. 12th Avenue. Office 201K

43210 Columbus, $\mathrm{OH}, \mathrm{USA}$

E-mail address: mauricio.rojas@osumc.edu
Received in original form: 19-06-2021

Accepted in final form: 12-07-2021 DOI: 10.23866/BRNRev:2020-0010 www.brnreviews.com 


\section{INTRODUCTION}

Idiopathic pulmonary fibrosis (IPF) is a chronic lung disease that develops, maybe in part, due to different cellular processes that cause a progressive increase in the aging of the lung tissue.

IPF prevalence is currently increasing, with Europe and North America being the regions with the highest rate: up to 3 to 9 cases per 100.000 persons-year ${ }^{1}$. Unfortunately, IPF patients have a poor prognosis since it has an average survival rate of 3.8 years among adults over 65 in the USA ${ }^{2}$. In recent years, the treatment of IPF has undergone substantial improvement due to the antifibrotic drugs pirfenidone and nintedanib, which have demonstrated in clinical trials their ability to decrease the functional deterioration with a slight improvement in the survival of patients with IPF. However, the destruction of the pulmonary parenchyma that causes the disease is not reversible, making pulmonary transplantation the only therapy for patients with IPF.

Understanding the different pathophysiological mechanisms involved at the cellular level in the development of IPF is essential to improve our knowledge of the disease, assess the prognosis of patients, and advance in the development of new curative therapies.

In this manuscript, we will review the cellular processes involved in lung aging in IPF, such as telomeric shortening, loss of proteostasis, mitochondrial dysfunction, or loss of repair capacity of mesenchymal progenitor cells. All this will contribute to the loss of correct function of the different cellular subpopulations in the lung parenchyma.

\section{ROLE OF LUNG CELLS IN FIBROSIS}

The histopathological characteristics of IPF include the abnormal increase of mesenchymal cells, dysmorphic epithelial cells, overproduction and disorganized collagen deposits in the extracellular matrix, distortion of the pulmonary architecture with the appearance of cystic spaces (honeycombing), as well as foci with accumulations of fibroblasts, which are characteristic of the usual interstitial pneumonia (UIP) pattern of IPF $^{3-7}$.

In animal models, using bleomycin instillation into the lung, pathogenesis of the pulmonary fibrosis shows a predominantly inflammatory cellular pattern formed by cells such as alveolar macrophages, eosinophils, neutrophils, and lymphocytes in response to tissue damage ${ }^{8-9}$. It has been proposed that alveolar macrophages could play a fundamental role given their ability to secrete proinflammatory molecules and profibrotic cytokines that would target the mesenchymal cells promoting collagen deposits ${ }^{4,10}$.

These findings, and recent data from singlecell RNA seq studies, had contributed to defining the current theory on the pathogenesis of IPF because its origin comes from the interaction of aberrant fibroblasts, epithelial cells, and activated macrophages. This explanation is supported by the presence of fibroblastic foci in areas with altered basal membrane directly below the areas with damaged epithelium without the presence of a significant inflammatory cellular infiltrate ${ }^{11-13}$. All this would lead to a progressive accumulation of extracellular matrix proteins that would damage the lung tissue structure and progressive fibrosis. 
TABLE 1. Summary of cellular mechanisms involved in pathogenesis of IPF

Cellular mechanisms
1. Alveolar epithelium cells:
- Changes in regular composition of alveolar epithelium: loss
of pneumocytes type I which entails and impaired gas exchange
through alveolar capillary membrane and proliferation
of pneumocytes type II with lack of normal reepithelialization
after a lung injury.
- Release of growth factors and cytokines after repeated
microlesions to epithelial cells: transforming growth factor
(TGF-B1), connective tissue growth factor (CTGF), fibroblast
growth factor (FGF-2) and interleukins (ILs) among them.
2. Fibroblast and myofibroblast:
- Recruitment and proliferation. Fibroblast foci.
- Increased production of collagen fibers with a decrease in
its degradation producing an abnormal deposit of collagen
in the extracellular tissue.
3. Mesenquimal stem cells:
- Decrease in their capacity of cellular regeneration due
to the loss of their reparative capacities.

The main cell types that intervene in the etiology of IPF are described in the following sections (Table 1).

\section{Role of epithelial cells in IPF}

Although the precise agents that initiate the changes observed in IPF are still unknown, a series of factors that could contribute to the development and perpetuation of the fibrotic response have been identified, among which are: predisposing genetic factors (mutations of surfactant proteins, MUC5B mutations, and telomeric shortening $)^{4,14-28}$, external triggers (tobacco, viral infections, environmental contaminants, chronic microaspiration, and drug toxicity $)^{29}$ as well as a dysregulation between oxidant and antioxidant factors and an imbalance between cell-derived cytokines Th1 and Th2 $2^{30-33}$.
It has been proposed that repeated subclinical lesions in the lung cause damage to the alveolar epithelium, subepithelial region, and basal endothelial membrane. This lesion allows entry into the alveolus of exudate with a high concentration of pro-inflammatory cytokines formed by cells of the mesenchymal lineage. The organization of the exudate leads to alveolar collapse, the juxtaposition of denuded alveolar walls, and the loss of surfac$\operatorname{tant}^{34}$. Both the epithelial lesion and the basal membrane appear to be necessary for the development of intraluminal fibrosis.

In the normal lung, the alveolar epithelium comprises type I epithelial cells, with a relatively small number of type II epithelial cells ${ }^{35}$. Type I epithelial cells cover $90 \%$ of the alveolar surface and are responsible for performing the exchange of gases through the alveolarcapillary membrane. On the other hand, type II epithelial cells have a role in the synthesis and secretion of surfactant, a compound formed by proteins and phospholipids that significantly reduces the surface tension inside the pulmonary alveoli, preventing its collapse. In a normal situation, type II epithelial cells are also responsible after an injury for the re-epithelialization of damaged alveoli ${ }^{36}$ restoring the numbers of type I and type II cells. However, in IPF, a loss of type I epithelial cells and a reduced reparative capacity of type II cells are observed. This lack of normal re-epithelialization could be due, in part, to aberrant activation of Wnt proteins after a lung injury. These proteins would inhibit the phosphorylation of beta-catenin by glycogen synthase kinase $3 \mathrm{~b}$ (GSK3b), preventing its translocation to the nucleus and activating the lymphoid enhancing factor/T-cell factor (LEF / TCF); this pathway would be involved in the 
activation of proliferation and absence of differentiation of type II cells ${ }^{37}$.

Data from single RNA sequence analysis of the IPF lungs have demonstrated a new basaloid epithelial cell that localizes in the IPF foci. In addition, these cells express markers of basal cells, cytokeratin 17, and are senescent. Thus, suggesting that these cells may be the ones trigging the aberrant interaction of epithelial cells and mesenchymal cells.

After the initial injury to these epithelial cells, the release of a series of growth factors and cytokines occurs. Among them, it is worth highlighting the transforming growth factor-beta (TGF-1 1$)^{38-39}$, which is one of the most potent regulators of connective tissue synthesis, increasing its production and inhibiting its proteases ${ }^{38-40}$. However, it can also induce other growth factors and cytokines involved in fibrosis, including connective tissue growth factor (CTGF), fibroblast growth factor (FGF-2), platelet-derived growth factor (PDGF), the insulin-like growth factor (IGF), and interleukins (ILs) ${ }^{41-42}$. Recent clinical studies support the role of TGF- 11 in the pathogenesis of IPF, having demonstrated the inhibition of fibrosis in experimental animals by reducing their expression, signaling, and activity.

Another cytokine involved in IPF is the tumor necrosis factor (TNF- $\alpha$ ), whose expression is increased in IPF, increasing the production of TGF- $\$ 1$ as well as stimulate the proliferation of fibroblasts and induce the synthesis of collagen ${ }^{43-44}$.

There is also overexpression of fibrotic cytokines, including monocyte chemoattractant protein 1 (MCP-1), IL-4, IL-13, FGF-2, IGF-1, PDGF, and GM-CSF. All these mediators would be involved in the activation and recruitment of circulating fibrocytes, thus perpetuating the response to cell damage.

Despite the role of inflammation in IPF pathogenesis being controversial, new insight provides evidence of the role of certain cell types that are activated in response to the release of chemokines and interleukines ${ }^{45}$ such as neutrophils (a major player in the acute phase of lung damage, which accumulation could lead to tissue remodeling and fibrosis), macrophages (they may exhibit anti-fibrotic and pro-fibrotic tissue regeneration functions, which depends on the cytokine environment, M2 macrophages appear to have a special role in the regulation of fibrosis being involved in acute exacerbations), fibrocytes (which contribute to fibroblast activation and production of extracellular matrix), type 2 innate lymphoid cells (that contribute to inflammatory responses and extracellular matrix homeostasis by releasing a wide array of mediators) and adaptive immune system (Th1 and Th2 cells involved with attenuation of fibrosis and activation of fibroblast respectively and B-cells whose concentration along with total immunoglobulins correlates with disease outcome).

\section{The role of fibroblasts in IPF}

The cytokines and growth factors secreted in response to repeated microlesions to epithelial cells result in the recruitment of fibroblasts derived from different sources: lung interstitial, peribranchial, pericytes, and mesenchymal stem cells. 
Subpopulations of fibroblasts in patients with IPF show some significant differences compared to isolated fibroblasts in normal lungs. These differences include increased cellular senescence with higher expression of $\$$-galactosidase, p21, p16, p53 and cytokines related to the senescence-associated secretory phenotype (SASP) as well as decreased proliferation/apoptosis compared to normal controls. Additionally, in a recent study ${ }^{46}$ it was observed that shorter telomeres, mitochondrial dysfunction and upon transforming growth factor- $ß$ stimulation increased markers of endoplasmic reticulum stress.

Fibroblast-derived myofibroblasts are cells that express characteristics of fibroblasts and smooth muscle cells and are identified by their expression of smooth muscle alpha actin $(\mathrm{AMS})^{47}$. After being recruited or differentiated from lung resident fibroblasts, both types of cells are organized in fibrotic foci, these being the histological characteristics of the UIP 3,7 . These foci of fibroblasts and myofibroblasts are located adjacent to areas of epithelial damage and of the basal membrane and precede the onset of advanced stage fibrosis. Myofibroblasts produce interstitial collagen in significantly greater amounts than fibroblasts ${ }^{48-49}$, leading to their accumulation in the extracellular matrix of the lung. Collagen type III is the predominant form of collagen in areas of initial fibrosis, while type I collagen predominates in areas of mature fibrosis.

In normal lungs, collagen is produced and continuously degraded by a family of matrix metalloproteinases (MMPs) that include collagenases ${ }^{50}$ secreted by fibroblasts, epithelial cells, neutrophils and macrophages; this process is tightly regulated to preserve the normal structure of the lung.

In patients with IPF, there is an imbalance between the interstitial collagenases and their tissue inhibitors. The increased synthesis of collagen accompanied by a decrease in its degradation would cause an abnormal deposition of collagen in the extracellular tissue.

The progressive deposit of extracellular matrix leads to a distorted pulmonary architecture with loss of capillary surface area and dysfunction of gas exchange units, and the fibrotic lung with resultant honeycombing areas has no potential capacity for regeneration and repair of lesions.

\section{Alteration on lung repair in IPF lungs}

In addition to the defects on type II epithelial cells, in IPF, there is a decrease in the capacity of cellular auto regeneration by mesenchymal progenitor cells due to the loss of their reparative capacities ${ }^{51}$, producing an imbalance between the rate of cellular renewal and differentiation ${ }^{52}$.

In IPF, the alteration of repair capacity and a distorted epithelial-mesenchymal communication produces a proliferation of abnormal bronchial epithelium and the lesion and hyperplasia of alveolar epithelial cells, particularly the phenotypic changes of the alveolar type cells $\mathrm{II}^{53}$.

In addition, mesenchymal cells in IPF show signs of senescence with increased p21 marker expression, shorter telomere length, longer 
duplication times, and changes in mitochondrial function and morphology (decrease in size, decreased oxygen consumption, and decreased glycolysis capacity). All this makes the mesenchymal cells less functional, as could be confirmed in studies based on the induction of fibrotic lung injury in mice with bleomycin, showing a less effective tissue repair by progenitor cells in sick subjects compared to healthy ones ${ }^{54}$.

Mesenchymal progenitor cells have been suggested as potentially therapeutic for patients with IPF due to their role in tissue repair and wound healing combined with their immunomodulatory properties ${ }^{55-56}$. It is known that these cells produce soluble factors such as fibronectin, periostin, lumican, and insulin-like growth factor-binding protein 7 (IGFBP7) that are involved in epithelial repairment. In addition, it has been shown in studies in mice with bleomycin-induced pulmonary fibrosis that mesenchymal cells exert a protective effect by improving inflammation and reducing the degree of injury and fibrosis ${ }^{57}$. This would lead to the conclusion that the implant of healthy mesenchymal progenitor cells could play a role in the future treatment of IPF to repair damaged lung tissue.

\section{Mechanisms of interaction among the different cellular populations}

Although not exactly known the initial lesion at the onset of the epithelial injury, it is generally considered that genetic predisposition (protein deficiency, telomere shortening) is associated with other external triggers such as lung toxins, infections, or repeated microaspirations could start the harmful process.
As a result of the damage caused on the alveolar epithelial and basal membrane, and activation of alveolar wall cells releasing growth factors and inflammatory cytokines including interleukins, MCP-1, and profibrotic molecules such as PDF and TGF-beta. Thus, the loss of alveolar cells and the presence of inflammatory molecules would generate a favorable microenvironment to perpetuate a pathological fibrotic process.

In turn, the soluble mediators produced by the epithelial and endothelial inflammatory cells would activate the circulating cells, including the fibroblasts, to maintain the injurious response.

The fibroblasts would respond to these molecules through their proliferation and differentiation into myofibroblasts grouped in fibrotic foci, which would precede the development of advanced phases of pulmonary fibrosis. On the other hand, the exhaustion and loss of the regenerative capacity of the mesenchymal progenitor cells exposed to the mentioned inflammatory microenvironment would play an essential role in the perpetuation of fibrosis.

The synthesis and progressive deposition of collagen in the extracellular matrix would alter the pulmonary structure and progressive and irreversible loss of its functional capacity.

\section{ROLE OF AGING IN IPF CELLULAR MECHANISMS}

Accelerated aging of the lung has been proposed as an essential mechanism in IPF. A series of aberrant hallmarks shared by chronic 
degenerating conditions such as cancer, fibrosis, and aging have been described. They include genomic instability, telomere attrition, epigenetic alterations, loss of proteostasis, $\mathrm{mi}-$ tochondrial dysfunction, cellular senescence, stem cell exhaustion, and altered intercellular communication (Table 2).

These mechanisms are involved in progressive loss of cellular physiological integrity, including different subpopulations of alveolar epithelial cells and interstitial fibroblast and mesenchymal progenitor cells. If their normal function is altered, they can derive into different phenotypes acquiring new roles. This would result in the aberrant activation of epithelial cells, which secrete numerous mediators, resulting in expansion of the fibroblast/myofibroblast population with the subsequent exaggerated accumulation of extracellular matrix and destruction of the lung architecture $^{58-61}$ (Fig. 1).

\section{*Genetic factors}

Different genetic disorders associated with IPF have been reported. One of the most studied is the gene MUC5B which presents overexpression due to the polymorphism of a single nucleotide (rs35705950) that codes for mucin 5B. It is known that this glycoprotein intervenes in mucociliary clearance and the response of innate immunity ${ }^{62}$. Although the mechanism by which overexpression of the gene increases the possibility of developing IPF up to $30-50 \%$ is still unknown, its identification would help for the early detection of the subjects with a higher risk of developing the disease in the most incipient phase $^{63}$.
TABLE 2. Aging mechanisms linked to IPF

\section{Aging mechanisms}

1. Internal factors.

- Defects in the mechanisms of DNA repairment causing gene variations which predispose to the development of IPF.

- Telomeric shortening producing loss of protective sequences and the ends of the chromosomes which limits the proliferative capacity and induce cellular senescence.

- Mitochondrial dysfunction in epithelial cells, fibroblast and macrophages inducing the production of reactive oxygen molecules, metabolic changes and secretion of cytokines that could lead to cellular apoptosis.

- Loss of protein homeostasis and reduction of elimination of the damaged proteins leading to anomalies that affects the normal cellular autophagy.

- Cellular senescence

2. External factors: smoking habit, environmental pollution, respiratory tract infections, gastroesophageal reflux.

Genes associated with a higher risk of suffering from IPF and associated with a worse prognosis are TERT, TERC, RTEL1, and PARN ${ }^{64}$. These are involved in the maintenance of telomere length, an essential mechanism to regulate cellular aging, as will be discussed later.

Other variations of genes predisposing to the disease (DSP, AKAP13, CTNNA, and DPP9) are known, which are responsible for adhesion and cell integration ${ }^{65-66}$. Among the genetic factors, the instability caused by defects in DNA repair mechanisms may contribute to the risk of developing pulmonary fibrosis. In addition, changes through DNA methylation, histone modification, and non-coding RNA have been proposed as a hallmark of aging by which chromatin remodeling would alter gene expression ${ }^{65}$. The dysregulation of growth factors and the activation of the IGF-1/AKT/mammalian target of rapamycin (mTOR) axis that also actively participates in the pathogenesis of IPF should be taken into account ${ }^{67}$. 


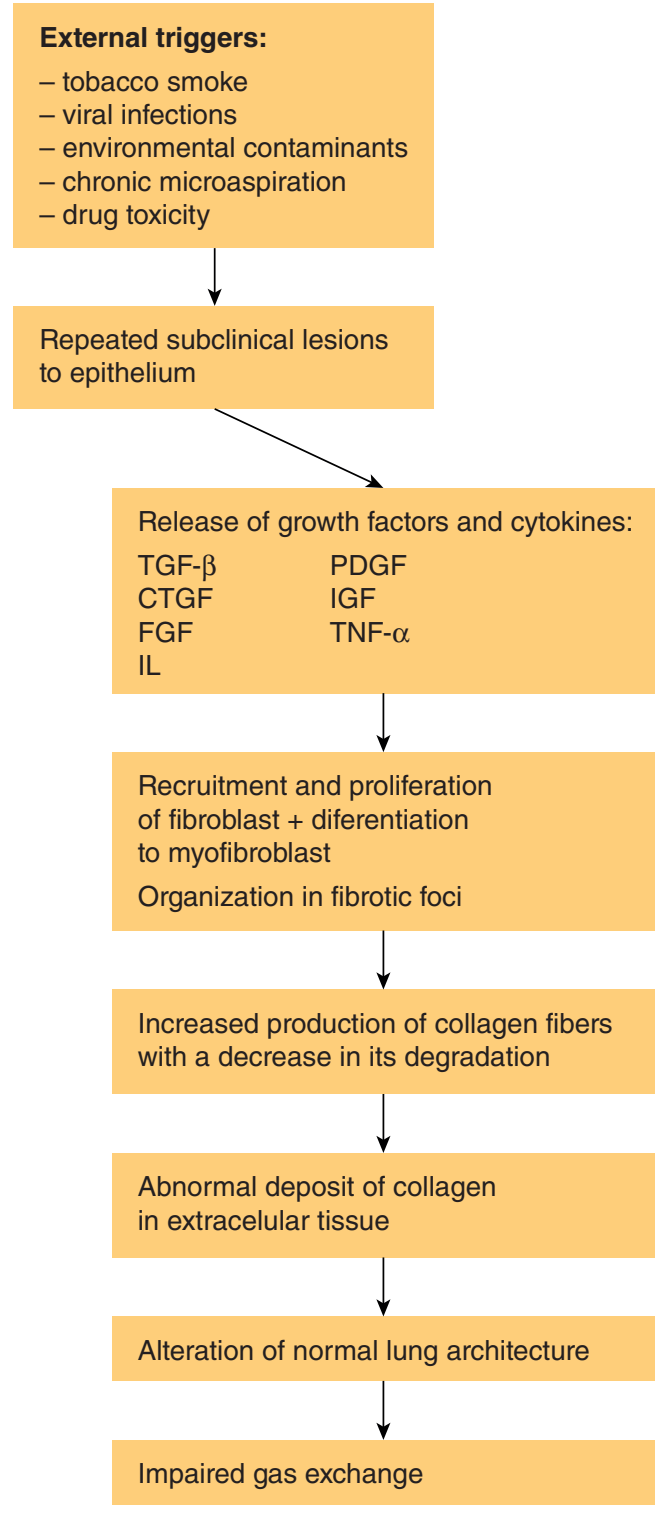

FIgURE 1. Schematic view of the pathophysiological mechanisms involved in the development of IPF.

CTGF: connective tissue growth factor; FGF: fibroblast growth factor; IGF: insulin-like growth factor; IL: interleukin; IPF: idiopathic pulmonary fibrosis; PDGF: platelet-derived growth factor; TGF- $\beta$ : transforming growth factor beta; TNF- $\alpha$; tumor necrosis factor-alpha.

Nevertheless, the genetic factors determine the expression of the disease and take into account the microenvironment to which the cells are exposed as well as different external factors that will constitute a risk factor for the

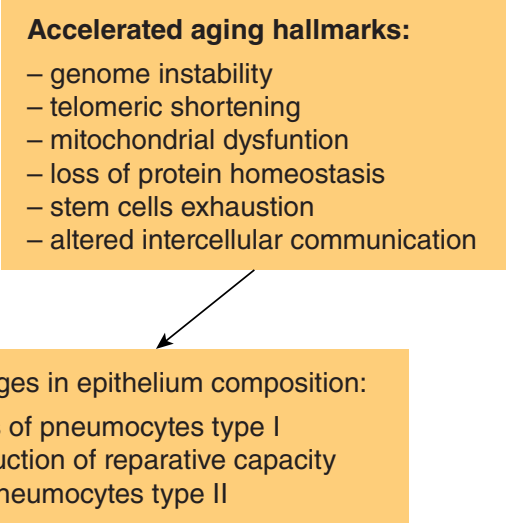

Changes in epithelium composition:

- loss of pneumocytes type

of pneumocytes type II development of the disease. Among these factors, we would highlight advanced age, male sex, or smoking habit as the best known. However, other factors have also been related, such as gastroesophageal reflux ${ }^{68}$, sleep 
apnoea/hypopnoea syndrome (SAHS) ${ }^{69}$, environmental pollution ${ }^{70}$, changes in the microbiome $^{71}$, infection by herpesvirus ${ }^{72}$, and other occupational exposures interstitial lung disease (ILD) (to vapors, gas, dust, and fumes) ${ }^{73}$.

\section{Telomeric shortening}

Telomeres are mainly involved in the control of cell growth. Although these are protective sequences at the ends of the chromosomes, they limit the proliferative capacity and induce cellular senescence, a determining factor in pulmonary fibrosis. Knowing if this alteration exists is essential since its severity correlates with the progression of the disease $\mathrm{e}^{74}$.

To avoid this process of DNA loss, there is a specialized DNA polymerase called telomerase, whose function consists in the repeated addiction of telomeres to the ends of the chromosomes ${ }^{75}$. Thus, the appearance of a mutation would cause enzymatic dysfunction and consequently telomeric shortening in the lung epithelial cells and several subclasses of leukocytes. Telomerase dysfunction together with mutations of surfactant proteins would be well described in cases of familiar IPF with a prevalence of $8-15 \%$ and $1-3 \%$ of cases of sporadic pulmonary fibrosis ${ }^{76}$.

We should highlight in this last subgroup the influence of other epigenetic factors, as discussed above, that could contribute to this process of accelerated cellular aging leading to telomere alteration in the absence of telomerase mutations ${ }^{77}$.

Recent studies have discovered a telomerase activator that can suppress the process of pulmonary fibrosis in animal models ${ }^{78}$. It is important, however, to underline the hypothesis that not all the telomere shortening process depends on this enzyme, but that other external factors intervene, also influencing the type of affected cell. In favor of this theory, there are studies carried out with mice with deficiency of the telomerase gene that do not develop signs of pulmonary fibrosis on their own, but that, in combination with exposure to toxic substances such as tobacco, can lead to pulmonary emphysema, a disease also related with cell aging ${ }^{79}$.

\section{Mitochondrial dysfunction}

The mitochondria are essential for the production of energy through oxidative phosphorylation and the regulation of critical cellular processes, including cell death and inflammation. Thus, a currently significant line of investigation includes the study of molecular mechanisms that regulate mitochondrial processes such as metabolic changes, production of reactive oxygen species (ROS), the appearance of mitochondrial DNA mutations as well as mitochondrial signaling anomalies ${ }^{80}$. Recently, dysregulation of many of these mechanisms has been identified in epithelial cells, fibroblasts, and lung macrophages in patients with $\mathrm{IPF}^{81}$.

Exposure to harmful agents could lead to cellular apoptosis through an increase in ROS production by epithelial cells ${ }^{82}$; said reactive oxygen molecules would produce cellular damage and, consequently, accelerated aging. Another route of ROS production would be through the alveolar macrophages that would also enhance the secretion of TGF-B1. This 
molecule is responsible for providing resistance to mitochondrial autophagy, being this the mechanism by which the cell eliminates those dysfunctional mitochondria. Multiple membrane proteins mediate this process. The best known is PINK1, having shown in several studies that its deficiency prevents the correct mitophagy and consequently produces the accumulation of dysfunctional mitochondria contributing to cellular senescence ${ }^{83}$.

However, the role of reactive oxygen species produced by mitochondria in cell aging is not yet clear, as other authors have described how, in animal models, the increase in ROS and oxidative damage do not accelerate cellular aging ${ }^{84-89}$. Instead, this could be explained by increased ROS production in response to stress and cell damage as a mechanism to maintain survival.

Another mechanism that induces the death of alveolar epithelial cells is the deficiency of deacetylase sirtuin-3 that would cause the inactivation of 8-oxoguanine DNA glycosylase. This would lead to a loss of its function to protect mitochondrial DNA from oxidative mechanisms ${ }^{90}$.

\section{Loss of proteostasis/autophagy}

Proteostasis (homeostasis of proteins) is the process that comprises the different pathways involved in the biogenesis, folding, function, and degradation of cellular proteins. With cellular aging, there is an alteration of the proteostasis and, consequently, anomalies that induce the stress of the endoplasmic reticulum (ER). This activates the adaptive unfolding protein response (UPR) that stops the general synthesis of proteins and increases the synthesis of chaperones (HSP70, HSP90, DNAJ / HSP40, chaperonin/HSP60, and small HSP), a set of proteins responsible for facilitating the folding of proteins, the traffic, and activity of lysosomal enzymes ${ }^{91}$. It has been observed that high levels of ER stress markers and activation of UPR are found in pulmonary alveolar epithelial cells ${ }^{92}$.

To eliminate excessive or misfolded proteins (proteolysis), the proteasomal system of ubiquitin and autophagy are used, which, in diseases associated with aging such as IPF, are reduced in parallel exacerbating stress enhancing the senescence of the cells involved in the pathogenesis of the disease ${ }^{93}$.

In pulmonary fibrosis, levels of light chain 3-II (LC3-II), a marker of autophagy, are significantly lower than in the general population ${ }^{94}$. However, the main one in charge of diminishing autophagy and enhancing the resistance to apoptosis of fibroblasts in the IPF is mTOR through the persistent activation of the mTORC1 pathway. This would be responsible for maintaining low levels of cellular autophagy. This pathway could suppose a possible therapeutic target to induce the apoptosis of the fibroblasts using two inhibitors: rapamycin and PP242, as some in vitro studies have show ${ }^{95}$. In addition, blocking the mTOR pathway by rapamycin has also been shown to attenuate pulmonary fibrosis induced by TGF- $\beta$ in mice ${ }^{96}$.

Studies are currently being conducted to prevent proteostasis loss by modifying proteolysis systems or altered chaperones such as $\mathrm{BiP}$ or HSP40 using compounds that modify intracytoplasmic calcium levels more significant 
transcription and translation of these proteins ${ }^{97}$. One of the most promising research drugs that rescue the folding of mutant proteins and promote toxic aggregates' clearance is the regulatory chaperone of proteostasis, 4-phenyl butyric acid (4-PBA) ${ }^{98}$. It is known that 4-PBA improves bleomycin-induced pulmonary fibrosis and decreases the expression of stress markers ER, collagen and $\alpha$-smooth muscle actin ( $\alpha \mathrm{SMA})^{99}$.

\section{Cellular senescence}

Cellular senescence is defined as a stable arrest of the cell cycle. It contributes to accelerating pulmonary aging, which in turn leads to an impaired lung function.

Several factors are related to the development of a dysfunctional cellular phenotype. For instance, toxins such as air pollution, lead, nitrosamines, or tobacco smoke generate ROS production and induce mitogenesis, therefore damaging DNA and causing telomere shortening $^{100}$. Other substances like chloroquine and heavy metals lead to a disruption of cellular proteostasis ${ }^{101}$.

These cellular alterations are associated with a shift in nutrient utilization to favor glycolysis instead of mitochondrial oxidative phospholiration $^{102}$. Due to inefficient and slow ATP production, the cell progressively accumulates excess ADLP and AMP and halts its capacity to proliferate since this process requires rapidly available energy. AMC is the preferred substrate for AMPK leading to activation of p53/p21 and Prb/p16 pathways ${ }^{103}$. The pyruvate produced is transferred to the mitochondria causing cellular swelling, a morphological biomarker to identify senescent cells. Also, the enzymatic conversion of pyruvate in the mitochondria generates Acetyl-CoA, which is utilized in the nucleus as acetyl donors to remodel histone structure and regulate cell transcription ${ }^{104}$.

All these combined lesions in the senescent cells are linked to the development of a senescent associated secretory phenotype (SASP) promoting the expression and release of highly inflammatory factors, including tumor suppressor proteins, transcription factors, microRNAs, growth factors, proteases, and inflammatory cytokines (ß-galactosidase, IL-6, IL-1b, NF-KB, p161NK4a) ${ }^{105}$. The secretory phenotype of these senescent cells is sufficient to trigger changes in the surrounding tissue and causing systemic effects.

In IPF, it is possible to detect these changes in all cell types involved in both animal and human models ${ }^{106}$. The senescence of myofibroblasts accompanied by the production of proinflammatory cytokines and metalloproteinases in the extracellular matrix contributes to the lung parenchyma's progressive fibrosis $^{107}$.

Advancing in the knowledge of the pathways of the senescence process would allow us to develop possible therapeutic targets. For instance, senescent fibroblasts exhibit an increased ROS-generating enzyme Nox4 and low levels of the critical mediator of the cellular antioxidant response pathways NFE2, generating an imbalance that contributes to the senescence process. It has been shown that treatment with a Nox inhibitor restores the redox balance and results in a decrease in senescent cells and a reduction in lung fibrosis ${ }^{108}$. 


\section{CONCLUSIONS}

Current theories on the pathogenesis of IPF include an initial lesion on the alveolar epithelial cells and the basal membrane that will trigger the production of inflammatory and profibrotic mediators, which in turn will induce changes in fibroblast proliferation, increased deposits of proteins in the extracellular matrix as well as cellular apoptosis and abnormal repair of tissue damage.

This pathology's progressive and irreversible nature means that it has a poor prognosis in the short term. Currently, few therapeutic options have been shown to modify the evolution of the disease.

Hence the need to understand the physiopathological mechanisms involved in the development of the disease. Only by understanding its pathogenic mechanisms it will be possible to recognize routes with the potential to become new therapeutic targets that can be used to improve the quality of life and the survival of these patients. Thus, the cellular mechanisms of aging continue to be a potential therapeutic target in which we must continue researching and investing resources to change the future of this disease.

\section{DISCLOSURES}

Dr. Cuerpo, Dr. Albacar, and Dr. Rojas have nothing to disclose.

\section{REFERENCES}

1. Hutchinson J, Fogarty A, Hubbard R et al. Global incidence and mortality of idiopathic pulmonary fibrosis: a systematic review. Eur Respir J. 2015; 46:795-806
2. Raghu G, Chen SY, Yeh WS et al. Idiopathic pulmonary fibrosis in US Medicare beneficiaries aged 65 years and older: incidence, prevalence, and survival, 2001-11. Lancet Respir Med. 2014;2:566-72.

3. Raghu G, Collard HR, Egan JJ et al. An official ATS/ERS/JRS/ALAT statement: idiopathic pulmonary fibrosis: evidence-based guidelines for diagnosis and management. Am J Respir Crit Care Med. 2011;183:788-824.

4. Gross TJ and Hunninghake GW. Idiopathic pulmonary fibrosis. N Engl J Med. 2001;345:517-25.

5. Katzenstein AL and Myers JL. Idiopathic pulmonary fibrosis: clinical relevance of pathologic classification. Am J Respir Crit Care Med. 1998;157: 1301-15.

6. Homer RJ, Elias JA, Lee CG et al. Modern concepts on the role of inflammation in pulmonary fibrosis. Arch Pathol Lab Med. 2011;135:780-8.

7. Flaherty KR, Travis WD, Colby TV et al. Histopathologic variability in usual and nonspecific interstitial pneumonias. Am J Respir Crit Care Med. 2001;164:1722-7.

8. Snider GL. Interstitial pulmonary fibrosis. Chest. 1986;89:115S-121S.

9. Reynolds HY, Fulmer JD, Kazmierowski JA et al. Analysis of cellular and protein content of broncho-alveolar lavage fluid from patients with idiopathic pulmonary fibrosis and chronic hypersensitivity pneumonitis. J Clin Invest. 1977;59:165-75.

10. Degryse AL and Lawson WE. Progress toward improving animal models for idiopathic pulmonary fibrosis. Am J Med Sci. 2011;341:444-9.

11. Kuhn C 3rd, Boldt J, King TE Jr et al. An immunohistochemical study of architectural remodeling and connective tissue synthesis in pulmonary fibrosis. Am Rev Respir Dis. 1989;140:1693-703.

12. Raghu G, Striker LJ, Hudson LD et al. Extracellular matrix in normal and fibrotic human lungs. Am Rev Respir Dis. 1985;131:281-9.

13. Hecker L and Thannickal VJ. Nonresolving fibrotic disorders: idiopathic pulmonary fibrosis as a paradigm of impaired tissue regeneration. Am J Med Sci. 2011;341:431-4.

14. Marshall RP, McAnulty RJ and Laurent GJ. The pathogenesis of pulmonary fibrosis: is there a fibrosis gene? Int J Biochem Cell Biol. 1997;29:107-20.

15. American Thoracic Society. Idiopathic pulmonary fibrosis: diagnosis and treatment. International consensus statement. American Thoracic Society (ATS), and the European Respiratory Society (ERS). Am J Respir Crit Care Med. 2000;161:646-64.

16. Talbot-Smith A, Syn WK, MacQuillan G et al. Familial idiopathic pulmonary fibrosis in association with bone marrow hypoplasia and hepatic nodular regenerative hyperplasia: a new "trimorphic" syndrome. Thorax. 2009;64:440-3.

17. Crossno PF, Polosukhin VV, Blackwell TS et al. Identification of early interstitial lung disease in an individual with genetic variations in ABCA3 and SFTPC. Chest. 2010; 137:969-73.

18. Schwartz D, Collins F. Medicine. Environmental biology and human disease. Science. 2007;316:695-6.

19. Wang Y, Kuan PJ, Xing C et al. Genetic defects in surfactant protein A2 are associated with pulmonary fibrosis and lung cancer. Am J Hum Genet. 2009;84:52-9.

20. Lawson WE, Grant SW, Ambrosini V et al. Genetic mutations in surfactant protein C are a rare cause of sporadic cases of IPF. Thorax. 2004;59:977-80.

21. van Moorsel CH, van Oosterhout MF, Barlo NP et al. Surfactant protein C mutations are the basis of a significant portion of adult familial pulmonary fibrosis in a dutch cohort. Am J Respir Crit Care Med. 2010;182:1419-25.

22. Bullard JE and Nogee LM. Heterozygosity for ABCA3 mutations modifies the severity of lung disease associated with a surfactant protein $C$ gene (SFTPC) mutation. Pediatr Res. 2007;62:176-9.

23. Seibold MA, Wise AL, Speer MC et al. A common MUC5B promoter polymorphism and pulmonary fibrosis. N Engl J Med. 2011;364:1503-12.

24. Armanios MY, Chen JJ, Cogan JD et al. Telomerase mutations in families with idiopathic pulmonary fibrosis. N Engl J Med. 2007;356:1317-26.

25. Tsakiri KD, Cronkhite JT, Kuan PJ et al. Adult-onset pulmonary fibrosis caused by mutations in telomerase. Proc Natl Acad Sci U S A. 2007;104: 7552-7. 
26. Cronkhite JT, Xing C, Raghu G et al. Telomere shortening in familial and sporadic pulmonary fibrosis. Am J Respir Crit Care Med. 2008;178:729-37.

27. Alder JK, Chen JJ, Lancaster L et al. Short telomeres are a risk factor for idiopathic pulmonary fibrosis. Proc Natl Acad Sci U S A. 2008;105:13051-6.

28. El-Chemaly S, Ziegler SG, Calado RT et al. Natural history of pulmonary fibrosis in two subjects with the same telomerase mutation. Chest. 2011; 139:1203-9.

29. Naik PK, Moore BB. Viral infection and aging as cofactors for the development of pulmonary fibrosis. Expert Rev Respir Med. 2010;4:759-71.

30. Hunninghake GW. Antioxidant therapy for idiopathic pulmonary fibrosis. N Engl J Med. 2005;353:2285-7.

31. Riches DW, Worthen GS, Augustin A et al. Inflammation in the pathogenesis of interstitial lung disease. In: Interstitial Lung Disease, 4th ed, King TE Jr, Schwarz MI (Eds), BC Decker, Hamilton, ON, Canada 2003. p.187.

32. Doherty DE, Hirose N, Zagarella L, Cherniack RM. Prolonged monocyte accumulation in the lung during bleomycin-induced pulmonary fibrosis. A noninvasive assessment of monocyte kinetics by scintigraphy. Lab Invest. 1992;66:231-42.

33. Fries KM, Blieden T, Looney RJ et al. Evidence of fibroblast heterogeneity and the role of fibroblast subpopulations in fibrosis. Clin Immunol Immunopathol. 1994;72:283-92.

34. Basset F, Ferrans VJ, Soler P et al. Intraluminal fibrosis in interstitial lung disorders. Am J Pathol. 1986;122:443-61.

35. Crapo JD, Barry BE, Gehr P et al. Cell number and cell characteristics of the normal human lung. Am Rev Respir Dis. 1982;126:332-7.

36. Mason RJ, Shannon JM. Alveolar type II cells. In: The Lung: Scientific Foundations, 2nd ed, Crystal RG, West JB, Weibel ER, Barnes PF (Eds), Lippincott-Raven, Philadelphia 1997. p.543.

37. Königshoff M, Kramer M, Balsara N et al. WNT1-inducible signaling protein-1 mediates pulmonary fibrosis in mice and is upregulated in humans with idiopathic pulmonary fibrosis. J Clin Invest. 2009;119:772-87.

38. Khalil N, O'Connor RN, Flanders KC, Unruh H. TGF-beta 1, but not TGF-beta 2 or TGF-beta 3, is differentially present in epithelial cells of advanced pulmonary fibrosis: an immunohistochemical study. Am J Respir Cell Mol Biol. 1996;14:131-8

39. Salez F, Gosset P, Copin MC et al. Transforming growth factor-beta1 in sarcoidosis. Eur Respir J. 1998;12:913-9.

40. Broekelmann TJ, Limper AH, Colby TV, McDonald JA. Transforming growth factor beta 1 is present at sites of extracellular matrix gene expression in human pulmonary fibrosis. Proc Natl Acad Sci U S A. 1991;88:6642-6.

41. Martin, TR. Overview of cytokine networks in lung injury. In: American Thoracic Society Continuing Education Monograph Series: "Cytokines and Pulmonary Infection," Pratter, MR, Nelson, S (eds) 1997. p. 19.

42. Shi-Wen X, Leask A, Abraham D. Regulation and function of connective tissue growth factor/CCN2 in tissue repair, scarring and fibrosis. Cytokine Growth Factor Rev. 2008;19:133-44.

43. Sime PJ, Marr RA, Gauldie D et al. Transfer of tumor necrosis factor-alpha to rat lung induces severe pulmonary inflammation and patchy interstitial fibrogenesis with induction of transforming growth factor-beta1 and myofibroblasts. Am J Pathol. 1998;153:825-32.

44. Ortiz LA, Lasky J, Lungarella G et al. Upregulation of the p75 but not the p55 TNF-alpha receptor mRNA after silica and bleomycin exposure and protection from lung injury in double receptor knockout mice. Am J Respir Cell Mol Biol. 1999;20:825-33.

45. Heukels P, Moor CC, von der Thusen, MS Wijsenbeek, M Koo. Inflammation and immunity in IPF pathogenesis and treatment. Respir Med. 2019; 147:79-91.

46. Alvarez D, Cardenes N, Sellares J, Bueno M, Corey C et al. IPF lung fibroblasts have a senescent phenotype. Am J Physiol Lung Cell Mol Physiol. 2017;311:L1164-73.

47. Gabbiani G. Evolution and clinical implications of the myofibroblast concept. Cardiovasc Res. 1998;38:545-8.

48. Zhang K, Rekhter MD, Gordon D, Phan SH. Myofibroblasts and their role in lung collagen gene expression during pulmonary fibrosis. A combined immunohistochemical and in situ hybridization study. Am J Pathol. 1994; 145:114-25.

49. Adler KB, Low RB, Leslie $\mathrm{KO}$ et al. Contractile cells in normal and fibrotic lung. Lab Invest. 1989;60:473-85.

50. Birkedal-Hansen H, Moore WG, Bodden MK et al. Matrix metalloproteinases: a review. Crit Rev Oral Biol Med. 1993;4:197-50.

51. López-Otín C, Blasco MA, Partridge L, Serrano M, Kroemer G. The hallmarks of aging. Cell. 2013;153:1194-217.

52. Mercado N, Ito K, Barnes PJ. Accelerated ageing of the lung in COPD: new concepts. Thorax. 2015;70:482-9.

53. King TE, Pardo A, Selman M. Idiopathic pulmonary fibrosis. Lancet. 2011;378:1949-61.

54. Cardenes N. Deficiencies In Mesenchymal Stem Cells From idiopathic Pulmonary Fibrosis Patients Result In Lower Capacity To Protect The LungFrom injury. Am J Respir Crit Care Med. 2016;193:A3084.

55. Rojas $\mathrm{M}, \mathrm{Xu} \mathrm{J}$, Woods $\mathrm{CR}$ et al. Bone marrow-derived mesenchymal stem cells in repair of the injured lung. Am J Respir Cell Mol Biol. 2005;33:145-52.

56. Alvarez D, Levine M, Rojas M. Regenerative medicine in the treatment of idiopathic pulmonary fibrosis: current position. Stem Cells Cloning. 2015 15;8:61-5.

57. Ortiz LA, Gambelli F, McBride C et al. Mesenchymal stem cell engraftment in lung is enhanced in response to bleomycin exposure and ameliorates its fibrotic effects. Proc Natl Acad Sci U S A. 2003;100:8407-11.

58. Yang J, Wheeler SE, Velikoff $\mathrm{M}$ et al. Activated alveolar epithelial cells initiate fibrosis through secretion of mesenchymal proteins. Am J Pathol 2013;183:1559-70.

59. Königshoff M. Lung cancer in pulmonary fibrosis: tales of epithelial cell plasticity. Respiration. 2011;81:353-8.

60. Königshoff M, Eickelberg O. WNT signaling in lung disease: a failure or a regeneration signal? Am J Respir Cell Mol Biol. 2010;42:21-31.

61. Bochaton-Piallat ML, Gabbiani G, Hinz B. The myofibroblast in wound healing and fibrosis: answered and unanswered questions. F1000Research. 2016;5:752.

62. Roy MG, Livraghi-Butrico A, Fletcher AA et al. Muc5b is required for airway defence. Nature. 2014;505:412-6.

63. Evans CM, Fingerlin TE, Schwarz MI et al. Idiopathic pulmonary fibrosis: a genetic disease that involves mucociliary dysfunction of the peripheral airways. Physiol Rev. 2016;96:1567-91.

64. Stuart BD, Lee JS, Kozlitina J et al. Effect of telomere length on survival in patients with idiopathic pulmonary fibrosis: an observational cohort study with independent validation. Lancet Respir Med. 2014;2:557-65.

65. Fingerlin TE, Murphy E, Zhang W et al. Genome-wide association study identifies multiple susceptibility loci for pulmonary fibrosis. Nat Genet 2013;45:613-20

66. Allen RJ, Porte J, Braybrooke R et al. Genetic variants associated with susceptibility to idiopathic pulmonary fibrosis in people of European ancestry: a genomewide association study. Lancet Respir Med. 2017;5:869-80.

67. Krein PM, Winston BW. Roles for insulin-like growth factor I and transforming growth factor-beta in fibrotic lung disease. Chest. 2002;122:289S-93S

68. Tobin RW, Pope CE II, Pellegrini CA, Emond MJ, Sillery J, Raghu G. Increased prevalence of gastroesophageal reflux in patients with idiopathic pulmonary fibrosis. Am J Respir Crit Care Med. 1998;158:1804-8.

69. Kim JS, Podolanczuk AJ, Borker P et al. Obstructive sleep apnea and subclinical interstitial lung disease in the Multi-Ethnic Study of Atherosclerosis (MESA). Ann Am Thorac Soc. 2017;14:1786-95.

70. Sack C, Vedal S, Sheppard L et al. Air pollution and subclinical interstitia lung disease: the Multi-Ethnic Study of Atherosclerosis (MESA) air-lung study. Eur Respir J. 2017;50:1700559.

71. Molyneaux PL, Willis Owen SA, Cox MJ et al. Host-microbial interactions in idiopathic pulmonary fibrosis. Am J Respir Crit Care Med. 2017;195 1640-50.

72. Tang Y-W, Johnson JE, Browning PJ et al. Herpesvirus DNA is consistently detected in lungs of patients with idiopathic pulmonary fibrosis. J Clin Microbiol. 2003;41:2633-40. 
73. Podolanczuk AJ, Oelsner EC, Barr RG et al. High attenuation areas on chest computed tomography in community-dwelling adults: the MESA study. Eur Respir J. 2016;48:1442-52.

74. Planas L, Arias-Salgado EG, Buendia-Roldán I et al. Clinical predictive factors and prognostic implications of telomere shortening in sporadic and familial idiopathic pulmonary fibrosis. Poster session presented at: ERS Research Seminar: Integrating Systems Biology Approach in Idiopathic Pulmonary Fibrosis Research. December 15-16, 2016.

75. Blackburn EH, Greider CW and Szostak JW. Telomeres and telomerase: the path from maize, Tetrahymena and yeast to human cancer and aging. Nat Med. 2006;12:1133-8.

76. Armanios M. Telomeres and age-related disease: how telomere biology informs clinical paradigms. J Clin Invest. 2013;123:996-1002.

77. Armanios M. Telomerase and idiopathic pulmonary fibrosis. Mutat Res. 2012;730:52-8

78. Le Saux CJ, Davy P, Brampton C et al. A novel telomerase activator suppresses lung damage in a murine model of idiopathic pulmonary fibrosis. PLoS One. 2013;8:e58423.

79. Alder JK, Guo N, Kembou F et al. Telomere length is a determinant of emphysema susceptibility. Am J Respir Crit Care Med. 2011;184:904-12.

80. Cloonan SM, Choi AM. Mitochondria in lung disease. J Clin Invest. 2016;126:809.

81. Mora AL, Bueno M and Rojas M. Mitochondria in the spotlight of aging and idiopathic pulmonary fibrosis. J Clin Invest. 2017;127:405-14.

82. Soberanes S, Panduri V, Mutlu GM et al. p53 mediates particulate matterinduced alveolar epithelial cell mitochondria-regulated apoptosis. Am J Respir Crit Care Med. 2006;174:1229-38.

83. Bueno M, Brands J, Voltz L et al. ATF3 represses PINK1 gene transcription in lung epithelia to control mitochondrial homeo-stasis. Aging Cell. 2018; 17: e12720.

84. Zhang J, Ney PA. Role of BNIP3 and NIX in cell death, autophagy, and mitophagy. Cell Death Differ. 2009;16:939-46.

85. Edgar D, Shabalina I, Camara Y et al. Random point mutations with major effects on protein-coding genes are the driving force behind premature aging in mtDNA mutator mice. Cell Metab. 2009;10:131-8.

86. Hiona A, Sanz A, Kujoth GC et al. Mitochondrial DNA mutations induce mitochondrial dysfunction, apoptosis and sarcopenia in skeletal muscle of mitochondrial DNA mutator mice. PLoS One. 2010;5:e11468.

87. Kujoth GC, Hiona A, Pugh TD et al. Mitochondrial DNA mutations, oxidative stress, and apoptosis in mammalian aging. Science. 2005;309:481-4.

88. Trifunovic A, Wredenberg A, Falkenberg M et al. Premature ageing in mice expressing defective mitochondrial DNA polymerase. Nature. 2004;429:417-23.

89. Vermulst M, Wanagat J, Kujoth GC et al. DNA deletions and clonal mutations drive premature aging in mitochondrial mutator mice. Nat Genet. 2008;40:392-4.

90. Jablonski RP, Kim SJ, Cheresh P et al. SIRT3 deficiency promotes lung fibrosis by augmenting alveolar epitelial cell mitochondrial DNA damage and apoptosis. FASEB J. 2017;31:2520-32.
91. Korfei M, Ruppert C, Mahavadi P et al. Epithelial endoplasmic reticulum stress and apoptosis in sporadic idiopathic pulmonary fibrosis. Am J Respir Crit Care Med. 2008;178:838-46.

92. Lawson WE, Crossno PF, Polosukhin VV et al. Endoplasmic reticulum stress in alveolar epithelial cells is prominent in IPF: association with alteredsurfactant protein processing and herpesvirus infection. Am J Physiol Lung Cell Mol Physiol. 2008;294:L1119-26.

93. Patel AS, Lin L, Geyer A et al. Autophagy in idiopathic pulmonary fibrosis. PLoS One. 2012;7:e41394.

94. Romero Y, Bueno M, Ramirez R et al. mTORC1 activation decreases autophagy in aging and idiopathic pulmonary fibrosis and contributes to apoptosis resistance in IPF fibroblasts. Aging Cell. 2016;15:1103-12.

95. Korfhagen TR, Le Cras TD, Davidson CR et al. Rapamycin prevents transforming growth factor-alpha-induced pulmonary fibrosis. Am J Respir Cell Mol Biol. 2009;41:562-72.

96. Mu TW, Ong DS, Wang YJ et al. Chemical and biological approaches synergize to ameliorate protein-folding diseases. Cell. 2008;134:769-81.

97. Kusaczuk M, Bartoszewicz, M and Cechowska-Pasko, M. Phenylbutyric acid: simple structure - multiple effects. Curr Pharm Des. 2015;21:2147-66.

98. Zhao H, Qin HY, Cao LF et al. Phenylbutyric acid inhibits epithelial-mesenchymal transition during bleomycin-induced lung fibrosis. Toxicol Lett. 2015;232:213-20.

99. Correia-Melo C, Marques FD, Anderson R, Hewitt G, Hewitt R et al. Mitochondria are required for pro-ageing features of the senescent phenotype. EMBO J. 2016;35:724-42.

100. Aivazidis S, Anderson CC, Roede JR. Toxicant-mediated redox control of proteostasis in neurodegeneration. Curr Opin Toxicol. 2019;13:22-34.

101. Gorgulis V, Adams PD, Alimonti A, Bennet DC, Bischof O et al. Cellular senescence: defining a path forward. Cell. 2019;179:813-27.

102. Gowans GJ, Hardie DG. AMPK: a cellular energy sensor primarily regulated by AMP. Biochem Soc Trans. 2014;42:71-5.

103. Korolchuk VI, Miwa S, Carroll B, Von Zglingicki T et al. Mitochondria in cell senescence: is motophagy the weakest link? EbioMedicine. 2017;21 7-13.

104. Fan J, Krautkramer KA, Feldman JL, Denu JM. Metabolic regulation of histone post-translational modifications. ACS Chem Biol. 2015;10:95-108.

105. Acosta JC, O'loghelen A, Banito A, Guijarro MV, Aurgert A et al. Chemokine signaling via the CXCR2 recpetor reinforces senescence. Cell. 2008;133: 10006-18.

106. Cloonan SM, Glass K, Laucho-Contreras ME et al. Mitochondrial iron chelation ameliorates cigarette smoke induced bronchitis and emphysema in mice. Nat Med. 2016;22:163-74.

107. Rodier F and Campisi J. Four faces of cellular senescence. J Cell Biol. 2011;192:547-56.

108. Bernard K, Logsdon NJ, Miguel V et al. NAPH oxidase 4 (Nox4) suppresses mitochondrial biogenesis and bioen-ergetics in lung fibroblasts via a nuclear factor erythroid-derived 2-like 2 (Nrf2)-dependent pathway. J Biol Chem. 2017;292:3029-38. 